\title{
FAMILIAL ATYPICAL HEMOLYTIC UREMIC SYNDROME WITH POSITIVE p.S1191L (c.3572C>T) MUTATION ON THE $C F H$ GENE: A SINGLE-CENTER EXPERIENCE
}

\author{
Ersoy Dursun $\mathrm{F}^{1, *}$, Yesil G' ${ }^{2}$, Sasak $\mathrm{G}^{3}$, Dursin $\mathrm{H}^{4}$
}

${ }^{*}$ Corresponding Author: Dr. Fadime Ersoy Dursun, Hematoloji Bilim Dal1, Istanbul Medeniyet Universitesi Tip Fakultesi, Dr. Erkin Cad. No. 6, 34722 Kadıköy, Istanbul, Turkiye. Tel.: +90-536-838-5101. Fax: +90-216-606-5210. E-mail: drfadimeersoy@yahoo.com.tr

\begin{abstract}
The atypical hemolytic uremic syndrome (aHUS) is characterized by thrombocytopenia, microangiopathic hemolytic anemia and acute kidney injury (AKI), which can exhibit a poor prognosis. Complement factor $\mathrm{H}$ $(\mathrm{CFH})$ gene mutations play a key role in this disease, which may be sporadic or familial. We studied 13 people from the same family, investigated for gene mutations of the familial aHUS after a family member presented to our emergency clinic with the aHUS and reported a family history of chronic renal failure. The p.S1191L mutation on the $\mathrm{CFH}$ gene was heterozygous in six people from the patient's family with the aHUS. One of these family members is our patient with acute kidney injury, and the other two are followed at the Nephrology Clinic, Medeniyat University, Goztepe Training and Research Hospital, Istanbul, Turkey, due to chronic renal failure. The other three family members showed no evidence of renal failure. The index case had a history of six sibling deaths; three died of chronic renal failure. Plasmapheresis and fresh frozen plasma treatment were administered to our patient. When the patient showed no response to this treatment, eculizumab (ECZ) therapy was started. The study demonstrated that thorough family history should be taken in patients with the aHUS. These patients may
\end{abstract}

\footnotetext{
${ }^{1}$ Department of Hematology, Medeniyet University, Goztepe Training and Research Hospital, Istanbul, Turkey

${ }^{2}$ Department of Medical Genetics, Bezmialem Vakif University, School of Medicine, Istanbul, Turkey

${ }^{3}$ Department of Nephrology, Medeniyat University, Goztepe Training and Research Hospital, Istanbul, Turkey

${ }^{4}$ Department of Pediatric Nephrology, Istanbul Health Sciences University, Okmeydani Training and Research Hospital, Istanbul, Turkey
}

have the familial type of the disease, and they should be screened genetically. Eculizumab should be the first choice in the treatment with plasmapheresis. It should be kept in mind that the use of ECZ as prophylaxis in posttransplant therapy is extremely important for preventing rejection.

Keywords: Complement factor $\mathrm{H}(\mathrm{CFH})$ gene; Eculizumab (ECZ); Familial atypical hemolytic uremic syndrome (aHUS); Plasmapheresis; p.S1191L mutation.

\section{INTRODUCTION}

Hemolytic uremic syndrome (HUS) is a type of thrombotic microangiopathy (TMA) characterized by thrombo-cytopenia, acute kidney injury (AKI), and microangiopathic hemolytic anemia [1-3]. Atypical HUS (aHUS) comprises around 5.0-10.0\% of all HUS cases and frequently leads to irreversible kidney injury, often with a worse prognosis $[1,2,4]$. Atypical HUS is a disease complex characterized by the uncontrolled over-activation of the alternative pathway of the complement system. Activation has been linked to mutations in complement factors in 50.0-60.0\% of cases [3]. Atypical HUS cases can be categorized as sporadic or familial. Familial aHUS requires diagnosing at least two aHUS cases in the same family over the past 6 months. Twenty percent of all aHUS patients are familial aHUS cases [5].

Genetic disorders such as gene mutations, rare variants, and risk haplotypes in familial aHUS and sporadic aHUS cases and developmental anomalies such as factor $\mathrm{H}$ against autoantibodies are found in $70.0 \%$ of patients [6]. The regulator of complement activation gene cluster on human chromosome 1q32 spans over a total of 21.45 $\mathrm{cM}$ and contains more than 60 gene codes, 15 of which are complement regulators. This code plays a vital role for both soluble and transmembrane proteins in regulating complement activity. These complement genes are 
arranged in tandem within two groups. Gene mutations usually occur in complementary genes such as factor $\mathrm{H}$ $(C F H)$, factor I $(C F I)$, factor B $(C F B)$, complement $3(C 3)$ and membrane cofactor protein ( $M C P$ or $C D 46)$. Although not all these gene mutations are detectable in the aHUS, they are the most frequently detected ones.

Data obtained from familial studies demonstrate that, due to a high level of incomplete penetrance of aHUS, $50.0 \%$ of persons carrying $C F H$ or $M C P$ mutations do not develop the disease. The genes for $\mathrm{CFH}$ and five $\mathrm{CFH}$ related proteins, CFHR1, CFHR2, CFHR3, CFHR4 and CFHR5, lie in a centromeric $360 \mathrm{~kb}$ segment [7-11]. Gene mutations and related proteins encoded by these genes play an important role in the course of the disease. Genetic studies in these patients do not include large series [12]. Venables et al. [13] previously showed, in a family with aHUS that non allelic homologous recombination results in the formation of a hybrid gene derived from exons 1-21 of $C F H$ and exons 5-6 of CFHR1. The protein product of this hybrid gene is identical to the aHUS associated $C F H$ mutant S1191L/V1197A, which arises through gene conversion [14]. We present a study on an aHUS patient where genetic screening was performed on family members to diagnose familial aHUS due to family history of chronic renal failure (CRF).

\section{MATERIALS AND METHODS}

Subject and Family Details. The study was carried out at the Department of Hematology and Nephrology, Medeniyet University, Goztepe Training and Research Hospital, Istanbul, Turkey. After the index case was detected, it was learned that there were other patients with CRF in the family history. After the family pedigree was generated, the $\mathrm{CFH}$ gene mutation analyses were performed for the family (Figure 1). Accordingly, 13 individuals from the same family, father and mother of the index case, his five siblings, as well as wives and children of two of the siblings, were included in the study. The first patient presented to our emergency clinic with AKI. The patient was diagnosed with aHUS as a result of clinical and laboratory evaluations. The patient reported a history of CRF cases in other family members; two of his siblings developed recurrent CRF after they received a renal transplant; six of his siblings died, three from CRF, and one of his uncles also died from CRF; therefore, gene mutation screening of this family was performed. These results from the patient files were examined and recorded.

Previous test results of the family members including the values of leukocytes, hemoglobin $(\mathrm{Hb})$, packed cell volume (PCV), platelets, glucose, blood urea nitrogen (BUN), creatinine $(\mathrm{Cr})$, total protein, albumin, aspartate aminotransferase (AST), alanine aminotransferase (ALT), $\gamma$-glutamyl transferase, alkaline phosphatase, lactate dehy-drogenase $(\mathrm{LDH})$, total bilirubin, peripheral smear, complement $3(\mathrm{C} 3)$, complement $4(\mathrm{C} 4)$, urine, protein in urine and $\mathrm{Cr}$, haptoglobin, ADAMTS-13 activity, and gene mutation analysis (CFH, CFI and CD46 gene sequence analysis) were obtained and recorded from the patient files.

Gene Mutation Screening. DNA was extracted from a whole blood sample using the QIA amp DNA Blood Mini Kit (Qiagen GmbH, Hilden, Germany), as previously described [15]. Exon-intron junctions of the genes $C F H$ [16], CFI [17], CD46 [18] and CFB [19], mutations of which are responsible for aHUS, were sequenced using next-generation sequencing (NGS). A heterozygous p.S1191L (c.3572C > T) mutation, which has previously been described as a disease-associated mutation in Human Gene Mutation Database (HGMD), was found on the $\mathrm{CFH}$ gene.

Ethics and Data Handling. The study was approved by the Medeniyet University Faculty of Medicine local Ethics Committee, Istanbul, Turkey. Before the study, in compliance with the principles of the World Medical Association Helsinki Declaration, written informed consent for publication was obtained from each family member after they were given a detailed explanation about the aims and scope of the study. In the case of children, written informed consent for publication was obtained from their parent or legal guardian. In the case of deceased family members, written informed consent for publication was obtained from their next of kin. Data were handled with respect for patient confidentiality and anonymity.

\section{RESULTS}

The laboratory findings of 13 patients included in the study are presented in Table 1 . The test results of our index case at the time of admission were as follows: $\mathrm{Hb} 7.8 \mathrm{~g} /$ $\mathrm{dL}$, PCV 0.23 L/L, platelets $56000.0 \mathrm{~mm}^{3}$, widespread schistocytes in peripheral blood smear, BUN $126.0 \mathrm{mg} / \mathrm{dL}$, Cr $7.8 \mathrm{mg} / \mathrm{dL}$, ADAMTS-13 activity 99.2\%, LDH 2350.0 IU/L and haptoglobin $<10.0 \mathrm{mg} / \mathrm{dL}$. Based on these results, the patient was diagnosed with aHUS. Of the 13 patients who were screened, three were diagnosed with $\mathrm{CRF}$, one being our index patient and the other two his siblings. The patient also reported six sibling deaths; three of them died of CRF. Besides, genetic screening results showed that the $C F H$ : p.S1191L mutation from the same family was heterozygous. The same mutation was also detected by Sanger sequencing in his mother (DT), three brothers (NT, CT, MT) and nephew (MUT) of the index case (AT), while the sister (SA) and one brother (MNT) did not have any mutations (Figure 1 and Table 1). 
Table 1. Demographic data and laboratory findings of the family members.

\begin{tabular}{|c|c|c|c|c|c|c|c|c|c|c|c|c|c|c|}
\hline Parameters & ST & DT & MNT & NT & FT & MUT & SA & AA & ŞA & FA & AT & CT & MT & Ref. Ranges \\
\hline Relationship & Father & Mother & Brother & Brother & $\begin{array}{l}\text { AT's } \\
\text { Aunt }\end{array}$ & $\begin{array}{l}\text { AT's } \\
\text { Nephew }\end{array}$ & Sister & \begin{tabular}{|l|} 
SA's \\
Husband
\end{tabular} & \begin{tabular}{|l|} 
AT's \\
Nephew
\end{tabular} & \begin{tabular}{|l|} 
AT's \\
Nephew
\end{tabular} & Index & Brother & Brother & \\
\hline Sex-Age (years) & M-78 & F-66 & M-38 & M-26 & F-26 & M-2 & F-30 & M-48 & M-12 & F-9 & M-28 & M-18 & M-23 & \\
\hline $\mathrm{WBC}\left(\mathrm{mm}^{3}\right)$ & 8900.0 & 7600.0 & 10500.0 & 5670.0 & 7400.0 & 19110.0 & 6600.0 & 8200.0 & 5800.0 & 7630.0 & 10300.0 & 5900.0 & 7870.0 & $4000.0-10000.0$ \\
\hline $\mathrm{Hb}(\mathrm{g} / \mathrm{dL})$ & 14.5 & 12.7 & 14.2 & 13.7 & 14.6 & 9.1 & 13.0 & 13.2 & 12.6 & 12.8 & 7.8 & 11.9 & 10.7 & $13.0-17.0$ \\
\hline PCV (L/fL) & 0.43 & 0.38 & 0.43 & 0.41 & 0.44 & 0.29 & 0.39 & 0.40 & 0.38 & 0.39 & 0.23 & 0.36 & 0.32 & $0.37-0.54$ \\
\hline Platelet count $\left(10^{9} / \mathrm{L}\right)$ & 256.0 & 368.0 & 210.0 & 162.0 & 432.0 & 450.0 & 282.0 & 342.0 & 323.0 & 410.0 & 56.0 & 173.0 & 120.0 & $150.0-500.0$ \\
\hline $\mathrm{BUN}(\mathrm{mg} / \mathrm{dL})$ & 32.0 & 58.0 & 36.0 & 19.0 & 25.0 & 23.0 & 21.0 & 24.0 & 26.0 & 21.0 & 126.0 & 113.0 & 122.0 & $18.0-55.0$ \\
\hline $\mathrm{Cr}(\mathrm{mg} / \mathrm{dL})$ & 0.78 & 0.92 & 0.84 & 0.82 & 0.67 & 0.25 & 0.76 & 0.48 & 0.64 & 0.72 & 7.80 & 7.67 & 7.60 & $0.72-1.25$ \\
\hline Total protein $(\mathrm{g} / \mathrm{dL})$ & 6.80 & 8.20 & 8.10 & 8.20 & 8.20 & 8.20 & 7.90 & 7.80 & 7.20 & 7.50 & 8.10 & 9.13 & 8.60 & $6.40-8.30$ \\
\hline Albumin $(\mathrm{g} / \mathrm{dL})$ & 4.20 & 4.30 & 4.40 & 4.70 & 4.80 & 4.29 & 4.60 & 4.10 & 4.00 & 4.30 & 4.40 & 5.10 & 4.40 & $3.50-5.520$ \\
\hline AST (IU/L) & 26.0 & 38.0 & 35.0 & 25.0 & 31.0 & 38.0 & 29.0 & 36.0 & 27.0 & 25.0 & 450.0 & 20.0 & 24.0 & $\begin{array}{l}<37.0 \\
\end{array}$ \\
\hline ALT (IU/L) & 24.0 & 36.0 & 29.0 & 15.0 & 36.0 & 18.0 & 33.0 & 28.0 & 18.0 & 21.0 & 630.0 & 6.0 & 11.0 & $<42.0$ \\
\hline GGT (IU/L) & 8.0 & 12.0 & 17.0 & 14.0 & 16.0 & 13.0 & 29.0 & 14.0 & 12.0 & 17.0 & 14.0 & 9.0 & 28.0 & $<64.0$ \\
\hline ALP (IU/L) & 68.0 & 58.0 & 59.0 & 75.0 & 120.0 & 198.0 & 48.0 & 110.0 & 86.0 & 84.0 & 65.0 & 82.0 & 123.0 & $<150.0$ \\
\hline LDH (IU/L) & 243.0 & 289.0 & 320.0 & 213.0 & 245.0 & 299.0 & 252.0 & 262.0 & 246.0 & 219.0 & 2350.0 & 248.0 & 259.0 & $125.0-220.0$ \\
\hline Glucose $(\mathrm{mg} / \mathrm{dL})$ & 86.0 & 78.0 & 96.0 & 84.0 & 78.0 & 108.0 & 89.0 & 82.0 & 89.0 & 74.0 & 86.0 & 99.0 & 82.0 & \begin{tabular}{|l|}
$70.0-105.0$ \\
\end{tabular} \\
\hline Total bilirubin $(\mathrm{mg} / \mathrm{dL})$ & 0.56 & 0.79 & 0.96 & 0.64 & 0.34 & 0.55 & 0.62 & 0.79 & 0.67 & 0.64 & 1.58 & 0.56 & 0.76 & \begin{tabular}{|l|}
$0.0-1.2$ \\
\end{tabular} \\
\hline Schistocyte & {$[-]$} & {$[+]$} & {$[-]$} & {$[-]$} & {$[-]$} & {$[-]$} & {$[-]$} & {$[-]$} & {$[-]$} & {$[-]$} & {$[+]$} & {$[+]$} & {$[+]$} & - \\
\hline $\mathrm{C} 3(\mathrm{mg} / \mathrm{dL})$ & 134.0 & 124.0 & 124.2 & 158.0 & 112.0 & 186.0 & 154.0 & 134.0 & 142.0 & 132.0 & 98.0 & 95.4 & 136.0 & $90.0-10.0$ \\
\hline $\mathrm{C} 4(\mathrm{mg} / \mathrm{dL})$ & 26.2 & 28.2 & 26.4 & 29.5 & 22.0 & 34.6 & 26.3 & 24.2 & 23.4 & 21.3 & 7.7 & 27.3 & 38.3 & \begin{tabular}{|l|}
$10.0-40.0$ \\
\end{tabular} \\
\hline Proteinuria & {$[-]$} & {$[+]$} & {$[-]$} & {$[-]$} & {$[-]$} & {$[+]$} & {$[-]$} & {$[-]$} & {$[-]$} & {$[-]$} & {$[+++]$} & anuric & anuric & - \\
\hline Hematuria & {$[-]$} & {$[+]$} & {$[-]$} & {$[-]$} & {$[-]$} & {$[+]$} & {$[-]$} & {$[-]$} & {$[-]$} & {$[-]$} & {$[+++]$} & anuric & anuric & - \\
\hline Protein/Cr (mg/mg) & $<0.2$ & $<0.2$ & $<0.2$ & $<0.2$ & $<0.2$ & 0.70 & $<0.2$ & $<0.2$ & $<0.2$ & $<0.2$ & 5.6 & anuric & anuric & $<0.2$ \\
\hline $\begin{array}{l}\text { ADAMTS-12 } \\
\text { activity }(\%)\end{array}$ & 97.00 & 96.00 & 84.20 & 77.11 & 94.30 & 120.40 & 67.00 & 88.50 & 92.60 & 102.00 & 99.27 & 98.40 & 83.11 & $40.00-130.00$ \\
\hline Haptoglobin (mg/dL) & 16.0 & 17.3 & 16.0 & 18.0 & 19.1 & 18.3 & 17.2 & 18.2 & 19.7 & 18.7 & $<10.0$ & 17.0 & 19.0 & $14.0-58.0$ \\
\hline$C H F:$ p.S1191L & $\mathrm{NM}$ & $\mathrm{H}$ & NM & $\mathrm{H}$ & NM & $\mathrm{H}$ & NM & NM & NM & NM & $\mathrm{H}$ & $\mathrm{H}$ & $\mathrm{H}$ & - \\
\hline Outcome & healthy & healthy & healthy & healthy & healthy & healthy & healthy & healthy & healthy & healthy & AKI & CRF & CRF & - \\
\hline
\end{tabular}

WBC: white blood cell count; $\mathrm{Hb}$ : hemoglobin; PCV: packed cell volume; BUN: blood urea nitrogen; Cr: creatinine;

AST: aspartate aminotransferase; ALT: alanine aminotransferase, GGT: $\gamma$-glutamyl transferase; ALP: alkaline phosphatase;

LDH: lactate dehydrogenase; C3: complement 3; C4: complement 4; CFH: complement factor H gene; NM: no mutataion;

$\mathrm{H}$ : heterozygous; AKI: acute kidney injury; CRF: chronic renal failure.

The family members showing gene mutations included the mother of the index case, three of his brothers, and one of his nephews. The laboratory results of these six cases and seven other family members are shown in Table 1. While all clinical and laboratory findings of the mother (DT), one sibling (NT) and this sibling's son (MUT), were normal, our index (AT) patient with the heterozygous gene mutation had AKI, and his two siblings (CT and MT) had CRF. These two siblings developed recurrent CRF after they received a renal transplant.

Sibling 1 (MT) developed AKI due to an unknown etiology at the age of 7. He applied to another hospital. His initial symptom was shortness of breath, and he was found to have severe hypertension, AKI with a serum $\mathrm{Cr}$ of $8.4 \mathrm{mg} / \mathrm{dL}$, anemia with $\mathrm{Hb}$ of $7.8 \mathrm{~g} / \mathrm{dL}$, and proteinuria. He underwent a kidney biopsy that revealed non specific findings. As there is a crescent in some areas in renal biopsy, it was thought that there might be rapidly progressive glo-merulonephritis. He received six high-dose pulse

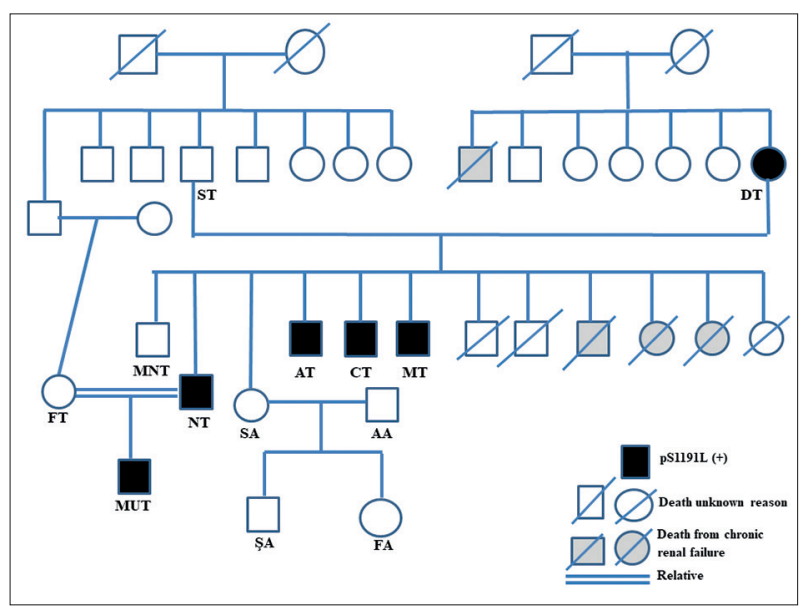

Figure 1. Pedigree of the studied family. Squares represent males and circles represent females. The filled black squares/ circles represent affected individuals, while white squares/circles represent unaffected individuals. Struck-through white squares/ circles represent those who died of unknown causes; those who died from CRF are struck-through and grey. 
steroids and continued with oral steroids and 10 sessions of plas-mapheresis. Despite therapy, the disease progress to $\mathrm{CRF}$, and the patient became hemodialysis-dependent. At that time, aHUS was not considered in this patient. The patient received hemodialysis treatment for 6 months, and then renal transplantation was performed from the father. Renal rejection developed 4 months after transplantation. Hemodialysis treatment was started again. The patient was diagnosed with familial aHUS after the diagnosis of our index case. The patient was taken back to the eculizumab (ECZ) treatment and transplantation program.

Sibling 2 (CT), a 18-year-old male, developed AKI due to an unknown etiology. He was admitted to another hospital with signs of AKI, like his brother. His initial symptom was shortness of breath, and he was found to have severe hypertension, AKI with a serum $\mathrm{Cr}$ of $9.1 \mathrm{mg} / \mathrm{dL}$, anemia with $\mathrm{Hb}$ of $8.8 \mathrm{~g} / \mathrm{dL}$, and proteinuria. Like his brother, he received steroid and plasmapheresis therapy. Despite therapy, the disease progress to the $\mathrm{CRF}$, and the patient became hemodialysis-dependent. After the patient received hemodialysis treatment for 11 months, he underwent a renal transplant (from a 35-year-old male patient who died of a cerebral hemorrhage). Renal rejection developed 3 months after transplantation. Hemodialysis treatment was started again. The patient was diagnosed with familial aHUS after the diagnosis of our index case. The patient was taken back to the transplantation program and eculizumab treatment.

Our index (AT) patient was treated with a total 20 sessions of plasmapheresis (initially, five sessions of plasmapheresis were performed, and then 15 more sessions were performed until the start of ECZ treatment) for 6 weeks and daily fresh frozen plasma therapy. However, upon insufficient response to this treatment, ECZ therapy was initiated. The patient showed a dramatic improvement after treatment with ECZ. The patient's serum Cr level was reduced to $0.8 \mathrm{mg} / \mathrm{dL}$. Moreover, when the patient became unable to receive ECZ treatment for a while, he once again developed AKI, with his blood $\mathrm{Cr}$ level increasing to 6.8 $\mathrm{mg} / \mathrm{dL}$. However, the patient's Hb level decreased to 6.4 $\mathrm{g} / \mathrm{dL}$ and platelet count to $78000 \mathrm{~mm}^{3}$. Furthermore, the patient developed dilated cardiomyopathy as in some cases reported in the literature [20]. Once the patient received regular ECZ therapy, his AKI symptoms and cardiomyopathy began to improve. The test results on the patient's last admission were as follows: $\mathrm{Hb} 13.6 \mathrm{~g} / \mathrm{dL}, \mathrm{PCV} 0.40$ $\mathrm{L} / \mathrm{L}$, platelet $345000.0 \mathrm{~mm}^{3}$, BUN $48 \mathrm{mg} / \mathrm{dL}$, Cr $1.8 \mathrm{mg} /$ $\mathrm{dL}, \mathrm{LDH} 210.0 \mathrm{IU} / \mathrm{L}$, and haptoglobin $18.2 \mathrm{mg} / \mathrm{dL}$. Longterm follow-up over 1 year showed stable renal function with no relapse. The patient is still being followed by the Departments of Hematology and Nephrology, Medeniyet University, Goztepe Training and Research Hospital, Istanbul, Turkey.

\section{DISCUSSION}

This study reports scanned results of a family who presented at our center. In six of 13 family members, the p.S1191L mutation on the $C F H$ gene was heterozygous. While three of these six family members (AT, CT and MT) had clinical and laboratory findings of the p.S1191L mutation on the $\mathrm{CFH}$ gene, two members (DT, NT and MUT) did not. There was no gene mutation or aHUS finding in the other seven family members. However, a total of six siblings of our index patient died. It was found that the cause of death of three was CRF, and the cause of death of the other three siblings was not known. In addition, one uncle of our index patient died from CRF. These findings show that the phenotype and penetrance of the $C F H$ gene mutations differ from person to person.

Some cases with the $C F H$ : p.S1191L gene mutation have been reported in the literature [21-23]. In the first of these articles, it was reported that a gene mutation [c.3572 (C>T), Ser1191Leu] was detected in a 12-year-old female patient. A renal transplant was performed on this patient after she developed chronic renal failure. Recurrence of aHUS has been reported after renal transplantation. The same gene mutation was detected in the younger twin sisters of this girl, but clinical and laboratory findings of aHUS did not develop [21]. The history of these cases is very similar to our cases. In another publication [24], a 7-month-old female baby who presented with aHUS associated with combined de novo CFH mutations (p.s1191L and V1197A), whose relapses could be treated with plasmapheresis at that time, but no information on ECZ treatment was provided. No results about the deaths of a mother and daughter were reported in another publication [16]. Therefore, it can be concluded that the appearance of this mutation is discouraging. However, as shown in our index case, positive results can be obtained with ECZ therapy. The significance of our study is that there were cases who are affected and not affected by the gene detected in the same family. This reflects the penetrance of the gene mutation in the literature. Another important result is the demonstration of the effectiveness of the ECZ therapy.

In aHUS, patients may be identified as familial or sporadic cases. In inherited cases, genetic mutations in $\mathrm{CFH}, \mathrm{CFI}, \mathrm{C} 3$ convertases, $\mathrm{C} 3$ and factor B, thrombomodulin, CD46 and MCP can lead to complement-related HUS. Other factors such as deficiency of metalloprotease activity that cleaves von Willebrand factor (VWF-CP or ADAMTS-13), CFI deficiency, and auto antibodies against CFH may also cause aHUS [25]. These mutations in complement components or regulatory proteins plays an important role in the pathogenesis of aHUS in 50.0-60.0\% of patients. These mutations cause mis regulation of the 
complementary alternative pathway in the endothelium, triggering attacks of thrombotic microangiopathy in the renal microvasculature and other vital organs [26-28]. A gene mutation in CFH (p.S1191L mutation in the $C F H$ gene) was found in the studied family. This gene encodes factor $\mathrm{H}$, which competitively binds to $\mathrm{C} 3 \mathrm{~b}$ to inhibit the production of $\mathrm{C} 3$ convertase, accelerates decay of $\mathrm{C} 3$ convertase, and acts as a cofactor of factor I to cleave $\mathrm{C} 3 \mathrm{~b}$ [29]. The $\mathrm{CFH}$ mutations, chiefly affecting the C-terminal, account for $15.0-20.0 \%$ of mutations in patients with aHUS. Antibodies against FH attach chiefly to the C-terminal, decrease $\mathrm{FH}$ binding to $\mathrm{C} 3 \mathrm{~b}$, and increase alternative pathway-dependent cell lysis [30].

The history of CRF and renal transplantation resulting in rejection in two patients was also associated with aHUS that might have occurred as a result of a mutation in this gene. No pathologies were detected in the other three family members with gene mutation, including the mother and a 2-year-old child. Therefore, the question arises as to whether factors such as female gender, not having experienced a triggering event, and young age could serve as protective features in the disease. The absence of any pathological findings in the third family member may have resulted from a mechanism that we cannot explain. There exist studies describing this phenomenon in the literature. Despite heterozygous pathogenic variants in complement genes often identified in diseased and healthy parents, the disease is often sporadic, which indicates that genetic mutations give rise to sensitivity, but they do not cause disease [31]. The disease occurred in approximately 50.0\% of the family members affected by the gene mutation by the time they reach 45 [32]. Arjona et al. [33] found that, in addition to the complement pathogenic mutation, carrying the MCPggaac haplotype or both the MCPggaac and the $\mathrm{CFH}-\mathrm{H} 3$ haplotypes, raises the aHUS penetrance to 9.4 and $14.5 \%$, respectively, by the age of 35 years, and the maximum aHUS penetrance to $15.0 \%$ (48 years) and $18.8 \%$ (37 years). In studies conducted on this subject, the results of genetic mutations were examined. These studies showed that the $\mathrm{C} 3$ mutation induces increased $\mathrm{C} 3$ convertase formation, thereby enhancing the alternative pathway [34]. The homozygous IVS-II $+2(\mathrm{~T}>\mathrm{G})$ mutation on the $C D 46$ gene may be clinically silent, especially in childhood, similar to the heterozygous mutation [35]. In this study, the presence of an aHUS-related progressive decline in renal function, microangiopathic hemolytic anemia, and thrombocytopenia in one person in the family was attributed to the heterozygous p.S1191L mutation on the $\mathrm{CFH}$ gene. This well-established feature of the disease has also been confirmed by our study. In the present study, three $(50.0 \%)$ of six patients with the heterozygous gene mutation developed the disease.
In addition to our index patient, the $C F H$ : p.S1191L mutation was heterozygous in his two siblings with CRF. These two patients had a kidney transplant history, but both developed acute rejections shortly after their transplant surgeries. Both of these patients still receive regular hemodialysis treatment 3 days a week. Other laboratory findings are normal in these patients, indicating that no triggering events of aHUS have so far occurred in their lives. The diagnosis of aHUS in his siblings and the detection of mutations on the $\mathrm{CFH}$ gene in the same gene with his siblings suggest that the presence of CRF and rejection after renal transplant in these patients might be associated with their aHUS, but they are not yet in the period of aHUS episodes.

In the treatment of atypical HUS, ECZ, a monoclonal antibody that inhibits complement protein $\mathrm{C} 5$, has been demonstrated to be an effective treatment option. In recent years, multicenter studies have shown that ECZ therapy rapidly improves the platelet count and renal functions in most patients after the first dose, eliminating the need for dialysis and plasma treatment. Eculizumab has been reported to be a fast, effective, and life-saving option in treating aHUS [36-39]. In the present study, our index patient with the $C F H$ : p.S1191L mutation was treated with ECZ, and he had a good response and survived. In a clinical trial of ECZ, a shorter interval between the clinical manifestation of aHUS and treatment initiation was associated with greater improvement in the estimated glomerular filtration rate [40]. Accordingly, we administered ECZ therapy to our index patient following plasmapheresis after the first admission. After ECZ treatment, the patient improved and his clinical and laboratory findings and returned to normal.

Limitations and Strengths. First of all, in our study, we should have performed genetic analysis on more family members, and secondly, we had to determine the causes of death of the deceased individuals of the family more clearly, but we could not.

Conclusions. This study identified six people who were heterozygous for the p.S1191L mutation on the $C F H$ gene in a family of 13 individuals who were genetically screened. While three of these cases showed no aHUS findings, we detected aHUS and CRF in the other three cases, which indicated that the genes affect the disease penetrance by about $50.0 \%$. A more thorough screening of all family relatives could detect a higher incidence of the gene in this family. Failure to diagnose aHUS as a cause of CRF in two individuals of this family during previous follow-up appointments and performing renal transplants before ECZ therapy prophylaxis may have caused renal transplant rejection in both patients. Therefore, this study has revealed that these family members should be closely monitored for early signs and symptoms of aHUS. The administration of 
ECZ is recommended for genetic variation carriers with a familial history or multiple relapses of aHUS. The availability of ECZ has fundamentally improved the outlook for patients with aHUS. This prospective study confirmed that ECZ inhibits complement-mediated thrombotic microangiopathy. Prevention of hemolysis and renal function improvement during ECZ therapy, without the need for plasma exchange/plasma infusion, represents an important clinical benefit. The ongoing extension treatment phase and a global aHUS registry study will provide further insights regarding the long-term use of ECZ in patients with familial aHUS.

Acknowledgments. This study, titled "Familial Atypical Hemolytic Uremic Syndrome with Positive pS1191L (c.3572C $>$ T) Mutation in CFH A SingleCenter Experience" was published as a pre-print in the BMC Nephrology journal (Fadime Ersoy Dursun et al.). However, BMC Nephrology rejected our article at the last stage. Moreover, we would like to thank all the participants in the study.

Declaration of Interest: The authors report no conflicts of interest. The authors alone are responsible for the content and writing of this article.

\section{REFERENCES}

1. Fakhouri F, Zuber J, Frémeaux-Bacchi V, Loirat C. Haemolytic uraemic syndrome. Lancet. 2017; 390(10095): 681-696.

2. Raina R, Krishnappa V, Blaha T, Kann T, Hein W, Burke L, et al. Atypical hemolytic-uremic syndrome: An update on pathophysiology, diagnosis, and treatment. Ther Apher Dial. 2019; 23(1): 4-21.

3. Noris M, Remuzzi G. Atypical hemolytic-uremic syndrome. N Engl J Med. 2009; 361(17): 1676-1687.

4. Moake JL. Thrombotic microangiopathies. N Engl J Med. 2002; 347(8): 589-600.

5. Noris M, Caprioli J, Bresin E, Mossali C, Pianetti G, Gamba S, et al. Relative role of genetic complement abnormalities in sporadic and familial aHUS and their impact on clinical phenotype. Clin J Am Soc Nephrol. 2010; 5(19): 1844-1859.

6. Dragon-Durey MA, Sethi SK, Bagga A, Blanc C, Blouin $\mathrm{J}$, Ranchin B, et al. Clinical features of anti-factor $\mathrm{H}$ autoantibody-associated hemolytic uremic syndrome. J Am Soc Nephrol. 2010; 21(12): 2180-2187.

7. Caprioli J, Noris M, Brioschi S, Pianetti G, Castelletti F, Bettinaglio P, et al. Genetics of HUS: The impact of MCP, CFH, and IF mutations on clinical presentation, response to treatment, and outcome. Blood. 2006; 108(4): 1267-1279.

8. Caprioli J, Bettinaglio P, Zipfel PF, Amadei B, Daina $\mathrm{E}, \mathrm{Gamba} \mathrm{S}$, et al. The molecular basis of familial hemolytic uremic syndrome: Mutation analysis of factor $\mathrm{H}$ gene reveals a hot spot in short consensus repeat. J Am Soc Nephrol. 2001; 12(2): 297-307.

9. Herbert AP, Kavanagh D, Johansson C, Morgan HP, Blaum BS, Hannan JP, et al. Structural and functional characterization of the product of disease-related factor H gene conversion. Biochemistry. 2012; 51(9): 1874-1884.

10. Perez-Caballero D, Gonzalez-Rubio C, Gallardo ME, Vera M, López-Trascasa M, Rodríguez de Córdoba $\mathrm{S}$, et al. Clustering of missense mutations in the $\mathrm{C}$-terminal region of factor $\mathrm{H}$ in atypical hemolytic uremic syndrome. Am J Hum Genet. 2001; 68(2): 478-484.

11. Fremeaux-Bacchi V, Fakhouri F, Garnier A, Bienaimé F, Dragon-Durey MA, Ngo S, et al. Genetics and outcome of atypical hemolytic uremic syndrome: A nationwide French series comparing children and adults. Clin J Am Soc Nephrol. 2013; 8(4): 554-562.

12. Schönauer R, Seidel A, Grohmann M, Lindner TH, Bergmann C, Halbritter J. Deleterious impact of a novel CFH splice site variant in atypical hemolytic uremic syndrome. Front Genet. 2019; 10: 465-471.

13. Venables JP, Strain L, Routledge D, Bourn D, Powell HM, Warwicker P, et al. Atypical haemolytic uraemic syndrome associated with a hybrid complement gene. PLoS Med. 2006; 3(10): e431-e442.

14. Heinen S, Sanchez-Corral P, Jackson MS, Strain L, Goodship JA, Kemp EJ, et al. De novo gene conversion in the RCA gene cluster (1q32) causes mutations in complement factor $\mathrm{H}$ associated with atypical hemolytic uremic syndrome. Hum Mutat. 2006; 27(3): 292-293.

15. Vaziri-Sani F, Holmberg L, Sjöholm AG, Kristoffersson AC, Manea M, Frémeaux-Bacchi V. Phenotypic expression of factor $\mathrm{H}$ mutations in patients with atypical hemolytic uremic syndrome. Kidney Int. 2006; 69(6): 981-988.

16. Richards A, Buddles MR, Donne RL, Kaplan BS, Kirk E, Venning MC, et al. Factor $\mathrm{H}$ mutations in hemolytic uremic syndrome cluster in exons 18-20, a domain important for host cell recognition. Am J Hum Genet. 2001; 68(2): 485-490.

17. Fremeaux-Bacchi V, Dragon-Durey MA, Blouin J, Vigneau C, Kuypers D, Boudailliez B, et al. Complement factor I: A susceptibility gene for atyp- 
ical haemolytic uraemic syndrome. J Med Genet. 2004;41(6): e84-e90.

18. Fremeaux-Bacchi V, Moulton EA, Kavanagh D, Dragon-Durey MA, Blouin J, Caudy A, et al. Genetic and functional analyses of membrane cofactor protein (CD46) mutations in atypical hemolytic uremic syndrome. J Am Soc Nephrol. 2006; 17(7): 2017-2025.

19. Goicoechea de Jorge E, Harris CL, Esparza-Gordillo J, Carreras L, Arranz EA, Garrido CA, et al. Gainof-function mutations in complement factor $\mathrm{B}$ are associated with atypical hemolytic uremic syndrome. Proc Natl Acad Sci USA. 2007; 104(1): 240-245.

20. Hu H, Nagra A, Haq MR, Gilbert RD. Eculizumab in atypical haemolytic uraemic syndrome with severe cardiac and neurological involvement. Pediatr Nephrol. 2014; 29(6): 1103-1106.

21. Olie KH, Florquin S, Groothoff JW, Verlaak R, Strain L, Goodship TH, et al. Atypical relapse of hemolytic uremic syndrome after transplantation. Pediatr Nephrol. 2004; 19(10): 1173-1176.

22. Olie KH, Goodship TH, Verlaak R, Florquin S, Groothoff JW, Strain L, et al. Posttransplantation cytomegalovirus-induced recurrence of atypical hemolytic uremic syndrome associated with a factor $\mathrm{H}$ mutation: Successful treatment with intensive plasma exchanges and ganciclovir. Am J Kidney Dis. 2005; 45(1): e12-e15.

23. Davin JC, Strain L, Goodship TH. Plasma therapy in atypical haemolytic uremic syndrome: Lessons from a family with a factor $\mathrm{H}$ mutation. Pediatr Nephrol. 2008; 23(9): 1517-1521.

24. Lapeyraque AL, Wagner E, Phan V, Clermont MJ, Merouani A, Fremeaux-Bacchi V, et al. Efficacy of plasma therapy in atypical hemolytic uremic syndrome with complement factor $\mathrm{H}$ mutations. Pediatr Nephrol. 2008; 23(8): 1363-1366.

25. Ariceta G, Besbas N, Johnson S, Karpman D, Landau $\mathrm{D}$, Licht $\mathrm{C}$, et al. Guideline for the investigation and initial therapy of diarrhea-negative hemolytic uremic syndrome. Pediatr Nephrol. 2009; 24(4): 687-696.

26. Hidalgo M, Pinto S, Tortajada A, Rodríguez de Córdoba S. Genetics of atypical hemolytic uremic syndrome (aHUS). Semin Thromb Hemost. 2014; 40(04): 422-430.

27. Afshar-Kharghan V. Atypical hemolytic uremic syndrome. Hematology Am Soc Hematol Educ Program. 2016; 2016(1): 217-225.

28. Feitz WJC, van de Kar NCAJ, Orth-Höller D, van den Heuvel LPJW, Licht C. The genetics of atypical hemolytic uremic syndrome. Med Genet. 2018; 30 (4): 400-409.
29. Boon CJF, van de Kar NC, Klevering BJ, Keunen JEE, Cremers FPM, Klaver CCW, et al. The spectrum of phenotypes caused by variants in the $\mathrm{CFH}$ gene. Mol Immunol. 2009; 46(8-9): 1573-1594.

30. Józsi M, Strobel S, Dahse HM, Liu WS, Hoyer PF, Oppermann $\mathrm{M}$, et al. Anti factor $\mathrm{H}$ autoantibodies block C-terminal recognition function of factor $\mathrm{H}$ in hemolytic uremic syndrome. Blood. 2007; 110(5): 1516-1518.

31. Cody EM, Dixon BP. Hemolytic uremic syndrome. Pediatr Clin North Am. 2019; 66 (1): 235-246.

32. Loirat C, Frémeaux-Bacchi V. Atypical hemolytic uremic syndrome. Orphanet J Rare Dis. 2011; 8: 60-90.

33. Arjona E, Huerta A, Goicoechea de Jorge E, Rodríguez de Córdoba S. Familial risk of developing atypical hemolytic-uremic syndrome. Blood. 2020; 136(13): 1558-1561.

34. Sartz L, Olin AI, Kristoffersson AC, Ståhl AL, Johansson ME, Westman K, et al. A novel C3 mutation causing increased formation of the $\mathrm{C} 3$ convertase in familial atypical hemolytic uremic syndrome. J Immunol. 2012; 188(4): 2030-2037.

35. Bhatia D, Khandelwal P, Sinha A, Hari P, Cheong HI, Bagga A. Incomplete penetrance of CD46 mutation causing familial atypical hemolytic uremic syndrome. Pediatr Nephrol. 2015; 30(12): 2215-2220.

36. Cao M, Leite BN, Ferreiro T, Calvo M, Fernández C, Alonso Á, et al. Eculizumab modifies outcomes in adults with atypical hemolytic uremic syndrome with acute kidney injury. Am J Nephrol. 2018;48(3): 225-233.

37. Loirat C, Fakhouri F, Ariceta G, Besbas N, Bitzan M, Bjerre A, et al. An international consensus approach to the management of atypical hemolytic uremic syndromein children. Pediatr Nephrol. 2016; 31(1):15-39.

38. Merrill SA, Brittingham ZD, Yuan X, Moliterno AR, Sperati CJ, Brodsky RA, et al. Eculizumab cessation in atypical hemolytic uremic syndrome. Blood. 2017; 130(3): 368-372.

39. Ruszkowski J, Heleniak Z, Dębska-Ślizień A. Atypical hemolytic uremic syndrome: A new drug program and first Polish adult patient treated with eculizumab. Pol Merkur Lekarski. 2018; 45 (267): 119-121.

40. Legendre CM, Licht C, Muus P, Greenbaum LA, Babu S, Bedrosian C, et al. Terminal complement inhibitor eculizumab in atypical hemolytic-uremic syndrome. N Engl J Med. 2013; 368(23): 2169-2181. 
